\title{
- Programa de Educação pelo Trabalho para a Saúde (PET- SAÚDE) sob a ótica dos preceptores
}

\author{
Vivian Breglia Rosa Vieira' \\ Elisabete de Oliveira ${ }^{2}$ \\ Carla Joana Guerini ${ }^{3}$
}

\section{RESUMO}

O presente trabalho objetivou avaliar a reorientação da formação profissional, desenvolvida pelo PET-Saúde, a partir da visão dos preceptores que participam do programa vinculado a uma instituição de ensino superior do oeste de Santa Catarina. Para isso realizou-se um estudo do tipo exploratório descritivo, através da aplicação de um questionário predominantemente qualitativo. Os resultados obtidos revelam satisfação dos preceptores com o programa. Os dados apontam que os preceptores percebem uma boa relação entre a academia e os serviços de saúde. Algumas dificuldades também foram apontadas durante a efetivação do programa, principalmente relacionadas à disponibilidade de tempo dos participantes. Conclui-se que, de maneira geral, os resultados são positivos e que os preceptores têm um olhar otimista sobre a reorientação profissional desenvolvida pelo programa em questão.

Palavras-chave: Preceptor. Formação profissional. PET-Saúde.

\section{The Program of Education through Work for Health (PET-HEALTH) from the perspective of the preceptors}

\section{ABSTRACT}

This study aimed to evaluate in the reorientation of vocational training developed by PET- Health, from the view of preceptors participating in the program linked to a higher education institution in the west

1 Mestre em Ciências da Saúde. Docente do Curso de Nutrição da União das Faculdades dos Grandes Lagos - UNILAGO. E-mail: vbrv2801@hotmail.com

2 Nutricionista. E-mail: betyy@unochapeco.edu.br.

3 Nutricionista. E-mail: carlajg@unochapeco.edu.br 
of Santa Catarina. For this we performed a study of descriptive exploratory, through the application of a predominantly qualitative questionnaire. The results show the satisfaction of preceptors with the the program. The data indicate that the preceptors realize a good relationship between academia and health services. Some difficulties were also identified during the execution of the program, mainly related to the availability of time of the participants. We conclude that, in general, the results are positive and that the preceptors have an optimistic look at the professional reorientation developed by the program in question.

Keywords: Preceptor. Professional qualification. PET-Health.

\section{El Programa de Educación para el Trabajo para la Salud (PET- SALUD) la perspectiva de preceptores}

\section{RESUMEN}

Este estudio tuvo como objetivo evaluar en la reorientación de la formación profesional desarrollada por PET-Salud, desde el punto de vista de los preceptores que participan en el programa vinculado a una institución de educación superior en el oeste de Santa Catarina. Para ello se realizó un estudio exploratorio de descriptivo, a través de la aplicación de un cuestionario predominantemente cualitativa. Los resultados muestran la satisfacción de preceptores para el programa. Los datos indican que los preceptores realicen una buena relación entre los servicios académicos y de salud. Algunas dificultades también fueron identificados durante la ejecución del programa, principalmente relacionados con la disponibilidad de los participantes de tiempo. Llegamos a la conclusión de que, en general, los resultados son positivos y que los preceptores tienen una mirada optimista en la reorientación profesional desarrollado por el programa en cuestión.

Palabras clave: Preceptor. Formación profesional. PET-Salud.

\section{Introdução}

Na última década, a formação dos profissionais de saúde tem sido reformulada com o intuito de atender às necessidades de saúde da população. Políticas públicas de educação e saúde promovidas a partir 
da parceria entre o Ministério da Educação (MEC) e o Ministério da Saúde (MS) sinalizaram a necessidade de uma reforma curricular nos cursos de graduação da área de saúde. A formalização dessa mudança teve seu marco com a instituição das Diretrizes Curriculares Nacionais (DCN) para os cursos de graduação no campo da saúde (BRASIL, 2011).

As DCN têm como ideia básica a flexibilização curricular, com vistas a possibilitar uma formação sólida, que qualifique o graduando para o enfrentamento das mudanças do conhecimento e seus reflexos no mundo do trabalho (BRASIL, 2006). Soares e Aguiar (2010) citam que as DCN sugerem que o conteúdo principal não esteja mais centrado em matérias, duração e carga horária, mas sim, no delineamento do perfil profissional, dos princípios que devem reger as profissões, bem como nas competências e habilidades requeridas.

As diretrizes orientam para currículos que contemplem elementos de fundamentação essencial no seu campo do saber ou profissão, numa concepção de que o indivíduo deve aprender a aprender, engajado num processo de educação permanente. Propõe-se que os cursos de graduação sejam baseados em aprendizagem ativa, centrada no aluno, como sujeito da aprendizagem e no professor, como facilitador e mediador deste processo de ensino-aprendizagem. Enfoca-se o aprendizado baseado em competências, em evidências científicas, na solução de problemas e orientado para a comunidade (BRASIL, 2006, p.13).

Apesar dos esforços do Ministério da Saúde e da Educação, isoladamente, a proposta das novas diretrizes não foi suficiente para promover mudanças significativas no processo de formação na área da saúde. Ainda parecia necessário criar novos mecanismos para que a formação fosse reorientada. Foi então, para atender essa demanda, que o Ministério da Saúde, através de sua Secretaria de Gestão do Trabalho e da Educação na Saúde (SGTES), em conjunto com a Secretaria de Educação Superior (SESU) e com o Instituto Nacional de Estudos e Pesquisas Educacionais Anísio Teixeira (INEP), elaborou o Programa Nacional de Reorientação da Formação Profissional em Saúde (Pró-Saúde). O Pró-Saúde foi lançado em 2005, por meio da Portaria Interministerial $n^{\circ}$. 2.101, de 3 de novembro de 2005, com a perspectiva de reorganizar o processo de formação, promovendo maior integração com o serviço público de saúde, com vistas a dar respostas às necessidades da população brasi- 
leira no que se refere à formação de recursos humanos, à produção do conhecimento e à prestação de serviços, fortalecendo o Sistema Único de Saúde (SUS) (BRASIL, 2005a).

Outra iniciativa governamental voltada para reorientação da formação profissional, que objetiva incentivar a inserção precoce de estudantes na atenção primária à saúde é o Programa de Educação pelo Trabalho para a Saúde (PET-Saúde), instituído pela Portaria Interministerial $n^{\circ} .1802$, de 26 de agosto de 2008 (BRASIL, 2008). O PET-Saúde é destinado a fomentar grupos de aprendizagem tutorial em áreas estratégicas para o SUS (BRASIL, 2010). De acordo com Ferraz (2012), a implementação do PET-Saúde foi estimulada pelo Pró-Saúde. A autora sugere que o programa está estimulando uma formação mais adequada às necessidades do SUS, já que incentiva que os serviços públicos de saúde sejam o principal cenário de prática educativa (FERRAZ, 2012).

Haddad e outros (2008) citam que o PET-Saúde foi inspirado no Programa Nacional de Inclusão de Jovens (ProJovem) e no Programa de Educação Tutorial (PET), ambos do Ministério da Educação. O ProJovem, instituído pela Lei n. 11.129, de 30 junho de 2005, é um programa destinado a executar ações integradas que propiciem aos jovens brasileiros elevação do grau de escolaridade, visando qualificação profissional (BRASIL, 2005b). Já o Programa de Educação Tutorial (PET), regido pela Lei n. 11.180, de 23 de setembro de 2005 (BRASIL, 2005c) e regulamentado pela Portaria n. 976, de 27 de julho de 2010, é um programa de educação tutorial desenvolvido a partir de cursos de graduação das instituições de ensino superior do País e é orientado pelo princípio da indissociabilidade entre ensino, pesquisa e extensão" (BRASIL, 2010).

O PET-Saúde é direcionado especialmente aos profissionais de saúde, do SUS, docentes e estudantes de graduação e, em parceria com as secretarias municipais de saúde, incentiva grupos de aprendizagem tutorial nas práticas de atenção à saúde do SUS (BRASIL, 2011). A proposta do PET-Saúde, assim como ocorre no Programa de Educação Tutorial, também é favorecer e reforçar a relação entre ensino, pesquisa e extensão (DIAS; LIMA; TEIXEIRA, 2013).

Cabe enfatizar que o PET-Saúde é um dispositivo de reorientação da formação profissional que favorece o processo de ensino-serviço e, para que isso aconteça, os sujeitos envolvidos nesse dispositivo, conforme determina a Portaria Interministerial no 422, de 3 de março de 2010, são estudantes, professores e profissionais dos serviços de saúde, 
designados, respectivamente de monitores, tutores acadêmicos e preceptores (BRASIL, 2010).

Os preceptores são profissionais de saúde que não estão vinculados diretamente à instituição de ensino superior e sim ao serviço de saúde. A principal função do preceptor é estreitar a distância entre o saber teórico e a prática, na formação dos estudantes. Orientar, dar suporte, ensinar e compartilhar experiências também são habilidades inseridas nas atribuições dos preceptores (BISPO; TAVARES; TOMAZ, 2014).

De acordo com Rocha, Warmling e Toassi (2016), a preceptoria é reconhecida como uma modalidade de ensino. Rodrigues (2012) cita que esse tipo de prática de ensino vem se destacando no cenário de formação de recursos humanos em saúde no Brasil. O objetivo é que os profissionais da saúde recebam, em seu contexto de trabalho, estudantes de diversos programas educacionais (RODRIGUES, 2012). Tal prática deve ser estabelecida e incentivada, principalmente, nos serviços públicos de saúde.

Segundo Rodrigues (2012), é uma realidade a necessidade de inserção do estudante nos serviços de saúde, principalmente do SUS e, em muitas instituições, consta no próprio contrato de trabalho, que o profissional exerça o papel de preceptor. Entretanto, ainda hoje, existem dificuldades e barreiras para a colocação de estudante nos cenários do SUS e o PET-Saúde pode estabelecer-se como um veículo importante para que a interação ensino-serviço-comunidade ocorra de fato. Ferreira, Foster e Santos (2012) enfatizam que um dos grandes desafios para efetivar a reorientação da formação profissional em saúde é reconhecer que a integração ensino-serviço-comunidade implica a construção de um novo modo de ensinar, aprender e fazer que envolva os diversos atores deste processo.

Diante do exposto, o presente trabalho buscou avaliar a reorientação da formação profissional desenvolvida pelo PET-Saúde, a partir da ótica de preceptores que participam do programa vinculado a uma universidade do oeste de Santa Catarina.

Para isso, realizou-se um estudo do tipo exploratório descritivo, através da aplicação de um questionário com abordagem predominantemente qualitativa. Este tipo de abordagem permitiu analisar a percepção dos participantes com relação ao objeto de estudo, o PET-Saúde. 
Para a coleta de dados, foi utilizada a técnica de entrevista semiestruturada. Os participantes foram convidados para integrar a pesquisa, por e-mail e/ou através de telefonema. As entrevistas aconteceram durante a realização de um encontro denominado "Seminário de Avaliação do Pró-Saúde e PET-Saúde", promovido por uma universidade do oeste de Santa Catarina. As entrevistas foram realizadas individualmente, respeitando a disponibilidade de cada participante. Todas as entrevistas foram gravadas e transcritas para posterior análise dos dados.

A interpretação dos dados foi realizada a partir da técnica de análise de conteúdo temática, proposta por Minayo (2013). A operacionalização, assim como o apontado pela literatura, se deu em três etapas: a pré-análise, a exploração do material e o tratamento e interpretação dos resultados obtidos (Minayo, 2013). Assim como sugere Minayo (2013), a pré-análise caracterizou-se como a fase de organização do estudo. Teve por objetivo operacionalizar e sistematizar as ideias, a fim de delimitar um esquema preciso para desenvolvimento das operações sucessivas. A segunda etapa, denominada de exploração do material, constituiu-se de análise do texto, sistematicamente. Por fim, a etapa de tratamento dos resultados obtidos e interpretação permitiu propor inferências e fazer correlações e interpretações de acordo com bases teóricas.

Minayo (2013) aponta que é importante garantir o anonimato dos sujeitos e o sigilo sobre os dados de pesquisa. Neste estudo foram utilizados todos os mecanismos possíveis para essa preservação, a fim de garantir o resguardo da identidade dos sujeitos. Nos resultados, foram utilizados códigos para apontamento de falas (E1, E2, E3, E4...).

Cabe ressaltar que esta pesquisa foi submetida e aprovada pelo Comitê de Ética em Pesquisa da Universidade Comunitária da Região de Chapecó (Unochapecó). Todos os participantes do estudo foram devidamente esclarecidos sobre o tema, os objetivos e os procedimentos do mesmo e assinaram um Termo de Consentimento Livre e Esclarecido (TCLE). Além disso, foi solicitada autorização para gravação das falas dos participantes, através de Termo de Consentimento de uso de voz. Esses procedimentos foram realizados a fim de se respeitar os princípios éticos da pesquisa envolvendo seres humanos, conforme a Resolução no. 466/2012 do Conselho Nacional de Saúde. 


\section{Resultados e discussão}

Foram entrevistados oito profissionais de saúde, preceptores dos grupos PET-Saúde de universidade do oeste catarinense, que atuam profissionalmente na atenção primária à saúde e que estavam vinculados ao programa há, pelo menos, um ano. É importante destacar que, conforme aponta a literatura, a pesquisa qualitativa não se baseia em critérios numéricos para garantir sua representatividade. Neste contexto, Minayo (2013) pontua que a amostragem boa é aquela que consegue abranger o problema investigado de tal forma que seja possível acessá-lo a partir de sua multidimensionalidade.

Optou-se por realizar a pesquisa apenas com preceptores que atuam na atenção primária uma vez que a grande meta do PET-Saúde é incentivar a inserção precoce de estudantes nesse nível de atenção à saúde (BRASIL, 2008). Dessa maneira, considerou-se importante conhecer a percepção desses profissionais sobre um programa que promove essa aproximação.

A atenção primária à saúde se constitui como porta de entrada preferencial do SUS. Caracteriza-se pela atenção dispensada nas Unidades Básicas de Saúde (UBS), diretamente com a comunidade, com o objetivo central de promoção de saúde e prevenção de doenças. Para o fortalecimento desse nível de atenção é necessário desenvolver processos de educação permanente para os trabalhadores e obter profissionais com formação e perfil adequado às necessidades de saúde da população (CONASEMS, 2011). De acordo com Trajman e outros (2009), a formação de profissionais de saúde com as competências para prestação de cuidados básicos deve se iniciar na graduação, considerando a atenção primária como um campo de práticas e também como um campo de conhecimentos que exige abordagens disciplinares e pedagógicas inteiramente novas. Nesse contexto, a articulação da relação entre estudantes e profissionais de saúde que atuam nesse nível de atenção à saúde é bem-vinda.

Além do critério relacionado à atuação na atenção primária, tomou-se o cuidado de incluir na pesquisa preceptores dos diversos projetos PET-Saúde existentes na universidade, a saber:

- PET-Saúde Redes de Atenção à Saúde:

- Projeto: Saúde e Meio Ambiente: Estudos Dirigidos em Grupos/Comunidades Específicas - Comunidades Indígenas; 
- Projeto: Atenção Domiciliar a Saúde de Idosos em Situação de Vulnerabilidade e Deficiência);

- PET-Saúde Vigilância em Saúde:

- Projeto: Integração Vigilância em Saúde e Redes de Atenção à Saúde;

- Projeto: Desafios do Ensino e do Serviço na Promoção e Proteção da Saúde Frente aos Acidentes de Trânsito e outras Violências;

- PET-Saúde Educação Permanente:

- Projeto: Fortalecendo o processo de educação permanente como instrumento para a qualificação da gestão do trabalho e da formação em saúde;

- PET-Saúde Rede de Cuidados à Saúde do Trabalhador:

- Projeto: Rede de Cuidados em Saúde do Trabalhador;

- Projeto: Rede de Cuidados em Saúde Mental;

- Projeto: Promoção da Saúde em Vivências Interdisciplinares e Multiprofissionais (VIM).

Cada um dos projetos PET-Saúde supracitados conta com a presença de estudantes, tutores acadêmicos e preceptores. A escolha de um preceptor de cada projeto, para integrar a pesquisa, foi baseada no fato de que os grupos são heterogêneos em si e entre si, trabalham temáticas distintas e, por isso, podem provocar percepções diferentes em seus componentes.

A metade dos entrevistados $(n=4)$ já participou de mais de um grupo PET-Saúde e por isso possui vínculo de cinco a seis anos com o dispositivo, os demais possuíam aproximadamente dois anos de vínculo. Esses dados demostram que os preceptores estão engajados com o programa e se comprometem com suas atividades por longos períodos de tempo, qualificando, assim, suas práticas na preceptoria.

Cabe destacar que os editais que regulamentam os projetos do PET-Saúde citam que compete às Instituições de Ensino Superior (IES) selecionar os tutores acadêmicos e os estudantes participantes. Cabe às Secretarias de Saúde selecionar os preceptores. Estas seleções se dão por meio de processo seletivo com critérios definidos por membros das IES e por gestores municipais e/ou estaduais de saúde. Existem diferenças no número de participantes, a depender do edital lançado, entretanto, no geral, cada grupo PET-Saúde conta com um ou dois tutores acadêmicos e entre dois e oito preceptores. Além disso, participam do 
programa de quatro a doze estudantes, sendo, no mínimo, de três cursos de graduação distintos.

Os tutores acadêmicos devem ter vínculo universitário, mestrado e, no mínimo, dois anos de experiência na área temática do projeto PET. Os preceptores devem ser profissionais de nível superior dos serviços de saúde, especialistas e ter dois anos de experiência em atividades relacionadas ao projeto. Tutores acadêmicos e preceptores devem ter dedicação às atividades junto aos estudantes de, no mínimo, oito horas semanais, sem prejuízo de suas atividades didáticas e de serviços de saúde, respectivamente (BRASIL, 2010).

Todos os participantes recebem auxílio financeiro. Os valores das bolsas para estudantes do PET-Saúde têm como referência as bolsas de iniciação científica. Já os tutores e preceptores recebem o valor referente às bolsas para o desenvolvimento tecnológico do Conselho Nacional de Desenvolvimento Científico e Tecnológico (CNPQ) (BRASIL, 2010).

\section{Caracterização do público que compôs a amostra do estudo}

Foram entrevistados quatro homens (50\%) e quatro mulheres (50\%), com idade entre 29 e 54 anos. Desses 62,5\% ( $n=5)$ são enfermeiros, $25 \%(n=2)$ são odontólogos e 12,5\% $(n=1)$ biólogo. Com relação ao tempo de formação, cinco deles (62,5\%) estavam formados, à época da coleta de dados, há mais de dez anos e os outros $(37,5 \%$; $n=3)$ há menos de dez anos. Desses, metade $(n=4)$ atua na área de formação há menos de 15 anos e outros $(n=4)$ atuam há mais de 15 anos.

Com relação à qualificação acadêmica pós-formação, seis participantes (75\%) relataram que cursaram especialização latu-sensu, 1 (12,5\%) possui pós-graduação stricto-sensu (nível de doutorado) e um (12,5\%) não realizou nenhuma qualificação acadêmica após a graduação.

Todos os participantes referiram realizar cursos de atualização profissional com o intuito de melhorar e aprimorar sua atuação ocupacional. Muitos desses cursos, segundo eles, são oferecidos pela Secretaria Municipal de Saúde e/ou pela IES a qual os projetos PET-Saúde estão vinculados. Tais dados demostram que a maioria desses profissionais dá importância ao processo contínuo de atualização profissional e que a Secretaria de Saúde e a universidade estimulam a educação continuada.

De acordo com a Organização Mundial de Saúde (OMS, 1982), educação continuada é definida como um processo que inclui todas 
as experiências posteriores à formação inicial, ou seja, é um processo permanente de educação, que complementa a formação básica, objetivando atualização e melhor capacitação de pessoas e grupos, frente às mudanças técnico-científicas e frente às necessidades sociais. Pode-se considerar, portanto, que os profissionais entrevistados zelam pela constante busca de aprimoramento e qualificação profissional.

Lima e Rozendo (2015, p.780) afirmam que "a preceptoria exige qualificação pedagógica, tanto nos aspectos teóricos quanto práticos". As autoras reforçam que a atuação do preceptor no processo de formação profissional contribui para as trocas de saberes e, essas trocas, favorecem o desenvolvimento de profissionais com perfis capazes de responder às necessidades do SUS. Os preceptores, nesse contexto, são mediadores e facilitadores no processo de aprendizagem e produção de saberes no mundo do trabalho (LIMA; ROZENDO, 2015).

\section{Percepções com relação ao pet-saúde}

Quando foram questionados com relação à motivação em participar do PET-Saúde, os preceptores referiram se motivarem pelo contato que estabelecem com os estudantes, pela possibilidade de contribuir com a formação em saúde e também pela oportunidade do trabalho multiprofissional e interdisciplinar.

A abordagem interdisciplinar e o trabalho em equipes multiprofissionais são raramente explorados pelas instituições de ensino superior. Tal fato se reproduz nas equipes de saúde, gerando ações isoladas de cada profissional, além de sobreposição e fragmentação das ações de cuidado (BRASIL, 2009). O PET-Saúde, portanto, assim como apontado pelos preceptores entrevistados, gera a oportunidade de praticar ações interdisciplinares e multiprofissionais, uma vez que envolve estudantes, professores e trabalhadores do SUS nas suas atividades. De acordo com Gattás e Furegato (2006), a interdisciplinaridade busca as relações de interdependência e de conexão recíproca entre disciplinas e áreas disciplinares. Caracteriza-se, portanto, pela intensidade das trocas entre especialidades e pelo grau de integração dos saberes. Já "a multidisciplinaridade é caracterizada pela justaposição de várias disciplinas em torno de um mesmo tema ou problema, sem o estabelecimento de relações entre os profissionais representantes de cada área" (ROQUETE et al., 2012, p. 465). 
Sobrinho e colaboradores (2011) consideram que a inserção de equipes multiprofissionais na atenção primária é, ainda, uma iniciativa inovadora que se configura como um desafio. Almeida e outros (2012) reforçam que a interdisciplinaridade é uma prática necessária para enfrentar as complexas necessidades de saúde das comunidades. Neste contexto, pode-se considerar que as práticas multiprofissionais e interdisciplinares vivenciadas no PET-Saúde podem contribuir para motivar a formação de profissionais que pratiquem ou ao menos busquem praticar o trabalho integrado e em equipe.

Muitos preceptores $(75 \% ; n=6)$ referiram que a prática da pesquisa, proporcionada pelo PET-Saúde, também influencia de maneira positiva a sua própria prática profissional. A aproximação com a pesquisa, segundo eles, aprimora e atualiza o olhar com relação aos casos que aparecem no dia a dia do trabalho.

Hoje, com certeza, tenho uma visão mais ampliada,
começo a deixar de só fazer a prática e começo a ter
uma visão mais cientifica do caso. (E2)
As pesquisas fazem com que voltemos o olhar para a
situação geral, não só para o habitual, da nossa área
de formação... A participação no PET-Saúde propor-
ciona mudanças com relação à organização e ao pla-
nejamento estratégico nas unidades de saúde. (E5)

Vale ressaltar que a elaboração do projeto de pesquisa é prática comum dos grupos PET-Saúde e requer aproximação com publicações científicas, recentes e clássicas, sobre as temáticas abordadas em cada caso. Tal fato oportuniza atualização com relação ao objeto de estudo. Ferraz $(2012$, p.168) aponta que um dos objetivos do PET-Saúde é estimular a atuação profissional "pautada pelo espírito crítico, pela cidadania e pela função social da educação superior, ambas orientadas pelo princípio da indissociabilidade entre ensino, pesquisa e extensão, preconizado pelo Ministério da Educação". Nesse sentido, a mesma autora aponta a pesquisa como uma forma de motivar os profissionais da área da saúde para a investigação e para a produção de estratégias e ações contextualizadas com a realidade local e cultural (FERRAZ, 2012).

Os preceptores foram incentivados a citar quais, na opinião deles, são os sujeitos beneficiados pelo programa. Metade deles $(n=4)$ citou apenas os estudantes e a comunidade e os outros citaram que os 
estudantes, a comunidade e os preceptores são beneficiados pelo PET-Saúde.

Todos que participam do programa são beneficiados. Os preceptores e os tutores trabalham para qualificar a formação dos estudantes, beneficiando-os. Os preceptores são beneficiados pela articulação serviço-ensino e também por terem oportunidade de se reciclar, através da pesquisa e pelo contato com a academia. O usuário é beneficiado no momento em que encontra uma equipe mais motivada, mais qualificada e mais preparada. (E3)

Chama atenção o fato de que nenhum entrevistado citou o tutor acadêmico como um beneficiado pelo programa. De acordo com publicação do Ministério da Saúde e da Educação, o tutor acadêmico, além de orientar estudante e preceptores com relação à pesquisa e produção de conhecimento relevante para o serviço de saúde, "terá a oportunidade de aprender também, e agregar ao curso de graduação, conhecimentos sobre o modelo de atenção, as necessidades de aprendizagem, a solução de problemas e a produção de conhecimento emanado do serviço" (BRASIL, 2009, p.34).

Pereira e Fracolli (2009) pontuam que programas como o PET-Saúde trazem benefícios para todos os seus participantes, uma vez que proporcionam aprendizado mútuo entre acadêmicos, preceptores, coordenação e tutoria. De acordo com as autoras, a aproximação entre as instituições de ensino e de serviço qualifica a prática profissional, uma vez que proporciona espaços de conversas e discussões sobre o papel de cada um dos atores envolvidos na formação profissional e na reorganização dos serviços (PEREIRA; FRACOLLI, 2009).

Quando incentivados a citar quais as potencialidades e fragilidades reconhecem no processo de formação do estudante que participa do PET-Saúde, a aproximação com o SUS foi citada como potencial. Pizzinato e outros (2012) apontam que a inserção dos acadêmicos nos serviços tem demonstrado ser uma excelente oportunidade para conhecer o funcionamento integral do sistema de saúde. Ainda nesse sentido, Fonseca e colaboradores (2014) citam que a aproximação com os cenários de prática e com a comunidade é capaz de auxiliar no processo formativo, oferecendo benefícios na esfera profissional e no âmbito da cidadania e da humanização. A fala de um dos entrevistados corrobora tais percepções: 
Aqueles que participam conseguem ter uma visão diferente do SUS: como as coisas acontecem no sistema, como ocorre o trabalho. (E1)

Questões relativas à disponibilidade de tempo foram apontadas, neste estudo, como pontos frágeis.

A maior fragilidade são os horários, pois são 8 horas semanais que devem ser cumpridas, e as vezes a escassez de tempo e o desencontro de horários acabam prejudicando o desenvolvimento no programa. (E4)

Oliveira e outros (2012), em estudo que buscou relatar o processo de implementação e descrever as ações desenvolvidas no PET-Saúde, na Universidade Federal de Mato Grosso do Sul, também identificou a incongruência de horários como fator limitante para o desenvolvimento do programa. Os autores apontaram que a dificuldade em articular horários para participação de todos nas atividades do programa acabava gerando desmotivação e abandono.

Lima e Rozendo (2015) também verificaram dificuldades relacionadas com a incompatibilidade de horários e apontaram que, para buscar solucionar tal situação, alguns preceptores mudaram suas rotinas de atendimento, de maneira a possibilitar o acolhimento dos estudantes. Além disso, as autoras citam que a utilização de recursos tecnológicos, como a criação de grupos de e-mails e páginas em redes sociais facilitaram o planejamento, a organização e o compartilhamento das ações realizadas.

Os preceptores foram questionados com relação ao seu próprio entendimento sobre o SUS antes e após participação no PET-Saúde e também sobre a percepção dos estudantes com relação ao sistema. Apenas um dos entrevistados relatou que seu próprio entendimento não se modificou. Todos os demais referiram que a participação no programa ampliou seus conhecimentos sobre o sistema de saúde brasileiro, uma vez que, no programa, puderam estudar a história de construção do sistema, suas legislações e portarias. Além disso, foi apontada a oportunidade de estudar e conhecer os sistemas de saúde de outros países.

Tive a oportunidade, através do PET, de conhecer a história do SUS, de conhecer o que ele representa, muitas legislações, portarias e as realidades dos sistemas de saúde de outros países. (E3) 
Depois do PET, se tem uma visão mais ampliada do SUS, antes era um pouco mais restrito. (E4)

O conhecimento que aumentou sobre o SUS, após a participação do programa, sobre determinadas legislações e portarias. (E5)

Os preceptores relataram que a participação no programa interfere de maneira positiva no entendimento do estudante sobre o sistema de saúde brasileiro. Foi comum a fala de que a participação no PET-Saúde amplia a percepção do acadêmico e, de certa forma, altera uma visão preconceituosa com relação ao SUS.

Muitos estudantes, principalmente os alunos das primeiras fases, acham que o SUS é coisa para pobre, não entendem o que é. Após a participação no PET isso muda. (E2)

O que posso perceber é que quem não participa do programa tem uma visão um pouco negativa sobre o sistema: "que não funciona, que demora"... tem uma visão como usuário. Depois de entrar no programa a visão muda. Pelo fato de poder estar na prática, dentro da unidade, de participar das atividades do dia-a-dia do trabalho, às vezes [o estudante] acaba percebendo que não é bem assim. (E5)

Os preceptores, frisa-se, que trabalham no SUS e, portanto, conhecem o seu dia a dia, podem contribuir para o aperfeiçoamento da crítica dos estudantes com relação ao sistema de saúde. Esta contribuição é essencial e valiosa, pois se entende que se o preceptor não está comprometido com o SUS ele, de certa maneira, acaba interferindo de maneira negativa na percepção e entendimento do estudante.

Por fim, os preceptores foram questionados sobre o fato de conversarem com os estudantes sobre as possibilidades de trabalho no SUS. Todos apontaram que sim. Foi referida também a modificação de planos de trabalho dos estudantes, após a participação no programa.

No início do projeto eu notava que a possibilidade de trabalho no SUS não era vista como um caminho. Mas depois, com o amadurecimento do projeto, eles veem sim o SUS como uma porta de trabalho. (E6)

Palmier e outros (2012, p.156) afirmam que os estudantes, em sua maioria, "não projetam o serviço público como espaço preferencial 
para atuação como profissionais de saúde". Entretanto, os mesmos autores apontam que após a inserção em espaços de saúde pública, os acadêmicos começam a ter percepções mais positivas com relação aos serviços (PALMIER et al., 2012). De acordo com Fonseca e colaboradores (2014), o conhecimento da prática no SUS incita e desperta os alunos para as possibilidades de exercício futuro da profissão no setor. Silva e outros (2012) corroboram ao afirmarem que foi possível verificar uma mudança na postura acadêmica depois da experiência vivenciada no PET-Saúde.

\section{Considerações finais}

Os preceptores que participaram dessa pesquisa visualizam o PET-Saúde de maneira muito positiva. Eles referiram se sentirem motivados a participar e continuar participando do programa, contribuindo, assim, com a formação de profissionais comprometidos com o sistema de saúde brasileiro. Destacaram que o programa proporciona, além de outros benefícios, a educação continuada, a atualização profissional e a interação com profissionais e futuros profissionais.

Foi importante notar que o conhecimento dos atores do PET-Saúde com relação aos sistemas de saúde existentes se ampliou. A participação no programa, segundo eles, proporcionou um maior entendimento sobre a história e as legislações do SUS e de outros sistemas de saúde ao redor do mundo. Ressalta-se que prática da pesquisa, dentro do PET-Saúde, proporciona o contato com materiais científicos e aproxima os profissionais de saúde dos critérios de atualização usados no meio acadêmico.

A maior fragilidade apontada pelos entrevistados foi a incompatibilidade de horários entre os participantes para realização das atividades do programa. Cabe ressaltar que é necessário desenvolver estratégias que minimizem esses entraves, uma vez que as trocas de saberes e o contato interpessoal são essenciais para que o programa atinja seus objetivos. A flexibilização nos horários do currículo pedagógico e na carga horária de trabalho beneficiaria a participação efetiva de todos nas ações do programa.

Diante dos resultados encontrados neste trabalho, ficou evidente que dispositivos de reorientação da formação profissional, sob o olhar dos preceptores, ampliam a visão dos participantes sobre a saúde pública, e também fortalece o trabalho no serviço público beneficiando to- 
dos os envolvidos: os estudantes, os preceptores, os tutores acadêmicos e, por consequência, a comunidade.

\section{Referências}

ALMEIDA, M. M.; MORAIS, R. P.; GUIMARÃES, D. F.; MACHADO, M. F. A. S.; DINIZ, R. C. M.; NUTO, S. A. S. Da teoria à prática da interdisciplinaridade: a experiência do Pró-Saúde Unifor e seus nove cursos de graduação. Revista Brasileira de Educação Médica. v.36, n.1, supl.1, p.119-126. 2012.

BISPO, E. P. F.; TAVARES, C. H. F.; TOMAZ, J. M. T. Interdisciplinaridade no ensino em saúde: o olhar do preceptor na Saúde da Família. Interface: comunicação, saúde, educação. Botucatu, v. 18, p. 337-350, 2014.

BRASIL. Ministério da Saúde; Ministério da Educação. Portaria Interministerial $\mathrm{n}^{\circ} 2.101$ de 3 de novembro de 2005. Institui o Programa de Reorientação da Formação Profissional em saúde - PRÓ-Saúde para os cursos de graduação em Medicina, Enfermagem e Odontologia. Diário Oficial da União. Brasília, 2005a.

BRASIL. Lei no 11.129, de 30 de junho de 2005. Institui o Programa Nacional de Inclusão de Jovens. Diário Oficial da União. Brasília, 2005b.

BRASIL. Ministério da Educação. Lei no 11.180, de 23 de setembro de 2005. Institui o Programa de Educação Tutorial - PET e dá outras providências. Diário Oficial da União. Brasília, 2005c.

BRASIL. Ministério da Saúde. A aderência dos cursos de graduação em Enfermagem, Medicina e Odontologia às Diretrizes Curriculares Nacionais. Brasília/DF: Ministério da Saúde, 2006.

BRASIL. Ministério da Educação; Ministério da Saúde. Portaria Interministerial $n^{\circ} 1.802$ de 26 de agosto de 2008. Institui o Programa de Educação pelo Trabalho para a Saúde - PET-Saúde. Diário Oficial da União. Brasília, 2008.

BRASIL. Ministério da Saúde. Ministério da Educação. Programa Nacional de Reorientação da Formação Profissional em Saúde - Prósaúde: objetivos e implementação e desenvolvimento potencial. $1^{\text {a.ed, }}$, 1a.reimp. Brasília: Ministério da Saúde, 2009. 
BRASIL. Ministério da Educação; Ministério da Saúde. Portaria Interministerial $n^{\circ} 422$ de 03 de março de 2010. Institui o Sistema de Informações Gerenciais do Programa de Educação pelo Trabalho para a Saúde - SIG-PET Saúde. Diário Oficial da União. Brasília, 2010.

BRASIL. Ministério da Saúde. Secretaria de Gestão do Trabalho e da Educação na Saúde - SGTES. A educação e o trabalho na saúde: a política e suas ações. Brasília: Ministério da Saúde, 2011.

CONASEMS - Conselho Nacional de Secretarias Municipais de Saúde. Atenção Básica que queremos. Organização: Nilo Brêtos Júnior. Ministério da Saúde, 2011

DIAS, H. S.; LIMA, L. D.; TEIXEIRA, M. A trajetória da política nacional de reorientação da formação profissional em saúde no SUS. Ciência \& Saúde Coletiva, Rio de Janeiro, v.18, n.6, p.1613-1624. 2013.

FERRAZ, L. O PET-Saúde e sua interlocução com o Pró-Saúde a partir da pesquisa: o relato dessa experiência. Revista Brasileira de Educação Médica. v.36, n.1, supl.1, p.166-171. 2012.

FERREIRA, J. B. B.; FORSTER, A. C.; SANTOS, J. S. Reconfigurando a interação entre ensino, serviço e comunidade. Revista Brasileira de Educação Médica. v.36, n.1, supl.1, p.127-133. 2012.

GATTÁS, M. L. B.; FUREGATO, A. R. F. Interdisciplinaridade: uma contextualização. Acta Paulista de Enfermagem. São Paulo, v.19, n.3, p.323-327. 2006.

FONSECA, G. S.; JUNQUEIRA, S. R.; ZILBOVICIUS, C; ARAÚJO, M. E. Educação pelo trabalho: Reorientando a Formação de Profissionais de Saúde. Revista Interface - Comunicação, Saúde, Educação. v.18, n.50, p.571-583. 2014.

HADDAD, A. E.; BRENELLI, S. L.; PASSARELLA, T. M.; RIBEIRO, T. C. V. Política Nacional de Educação na Saúde. Revista Baiana de Saúde Pública, Salvador, v.32, supl.1, p.98-114, out., 2008.

LIMA, P. A. B.; ROZENDO, C. A. Desafios e possibilidades no exercício da preceptoria do Pró-PET-Saúde. Revista Interface - Comunicação, Saúde, Educação. v.19, supl.1, p.779-791. 2015

MINAYO, M. C. S. O desafio do conhecimento: pesquisa qualitativa em saúde. 13.ed, São Paulo: Hucitec, 2013. 
OLIVEIRA, M. L.; MENDONÇA, M. K.; FILHO, H. L. A.; COELHO, T. C.; BENETTI, C. N. PET-Saúde: (in)formar e fazer como processo de aprendizagem em serviços de saúde. Revista Brasileira de Educação Médica. v.36, n.1, supl.2, p.105-111. 2012.

OMS, Organización Mundial Salud. Continuando La educación de los trabajadores de salud: principio e guias para el desarrolo de um sistema. Genebra, 1982.

PALMIER, A. C.; AMARAL, J. H. L.; WERNECK, M. A. F.; SENNA, M. I. B.; LUCAS, S. D. Inserção do aluno de Odontologia no SUS: contribuições do Pró-Saúde. Revista Brasileira de Educação Médica. v.36, n.1, supl.2, p.152-157. 2012.

PEREIRA, J. G.; FRACOLLI, L. A. A contribuição da articulação ensinoserviço para a construção da vigilância da saúde: a perspectiva dos docentes. Revista Latino-Americana de Enfermagem. v.17, n.2. 2009.

PIZZINATO, A.; GUSTAVO, A. S.; SANTOS, B. R. L.; OJEDA, B. S.; FERREIRA, E.; THIESEN, F. V.; CREUTZBERG, M.; ALTAMIRANO, M.; PANIZ, O.; CORBELLINI, V. L. C. A integração ensino-serviço como estratégia na formação profissional para o SUS. Revista Brasileira de Educação Médica. v.36, n.1, supl.2, p.170-177. 2012.

ROCHA, P F.; WARMLING, C. M.; TOASSI, R. F. C. Preceptoria como modalidade de ensino na saúde: atuação e características do preceptor cirurgião-dentista da atenção primária. Revista saberes plurais: educação na saúde. Porto Alegre, v. 1, n. 1, p. 96-112, 2016.

RODRIGUES, C. D. S. Competências para a preceptoria: construção no Programa de Educação pelo Trabalho para a Saúde. 2012. Dissertação (Mestrado em enfermagem) Universidade Federal do Rio Grande do Sul. Porto Alegre-RS, 2012.

ROQUETE, F. F.; AMORIM, M. M. A.; BARBOSA, S. P.; SOUZA, D. C. M.; CARVALHO, D. V. Multidisciplinaridade, interdisciplinaridade e transdisciplinaridade: em busca de diálogo entre saberes no campo da saúde coletiva. Revista de Enfermagem do Centro Oeste Mineiro. Divinópolis, v.2, n.3, p.463-474, set./dez., 2012.

SILVA, R. O. B.; ALVES, E. D.; CARVALHO, D. S. L.; MESQUITA, D. M. Programa PET-Saúde: trajetória 2009-2010, na Universidade de Brasília. Saúde em Debate. v.36, n.95, p.678-683. Rio de Janeiro: out/dez, 2012. 
SOARES, N. T.; AGUIAR, A. C. Diretrizes curriculares nacionais para os cursos de nutrição: avanços, lacunas, ambiguidade e perspectivas. Revista de Nutrição, Campinas, v.23, n.5, p.895-905, set./out. 2010.

SOBRINHO, T. A. O.; MEDEIROS, C. P. P.; MAIA, M. R.; REIS, T. C.; MIRANDA, L. P.; COSTA, P. F. Integração Acadêmica e Multiprofissional no Pet-Saúde: Experiências e Desafios. Revista da ABENO. v.11, n.1, p.39-42. 2011.

TRAJMAN, A.; ASSUNÇÃO, N.; VENTURIL, M.; TOBIAS, D.; TOSCHI, W.; BRANT, V. A preceptoria na rede básica da Secretaria Municipal de Saúde do Rio de Janeiro: opinião dos profissionais de Saúde. Revista Brasileira de Educação Medica. v.33, n.1, p.14-32. 2009.

Recebido: Abril/2018

Aceito: Dezembro/2019 